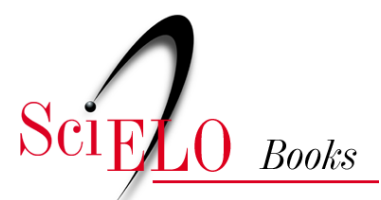

\title{
27. Ambroise Paré, o Cirurgião que Não Sabia Latim
}

\author{
Joffre Marcondes de Rezende
}

\section{SciELO Books / SciELO Livros / SciELO Libros}

REZENDE, J. M. Ambroise Paré, o Cirurgião que Não Sabia Latim. In: À sombra do plátano: crônicas de história da medicina [online]. São Paulo: Editora Unifesp, 2009, pp. 245-249. História da Medicina series, vol. 2. ISBN 978-85-61673-63-5. https://doi.org/10.7476/9788561673635.0028.

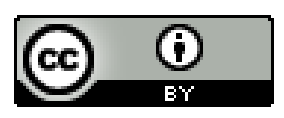

All the contents of this work, except where otherwise noted, is licensed under a Creative Commons Attribution 4.0 International license.

Todo o conteúdo deste trabalho, exceto quando houver ressalva, é publicado sob a licença Creative Commons Atribição 4.0.

Todo el contenido de esta obra, excepto donde se indique lo contrario, está bajo licencia de la licencia Creative Commons Reconocimento 4.0. 


\title{
Ambroise Paré, o Cirurgião que Não Sabia Latim
}

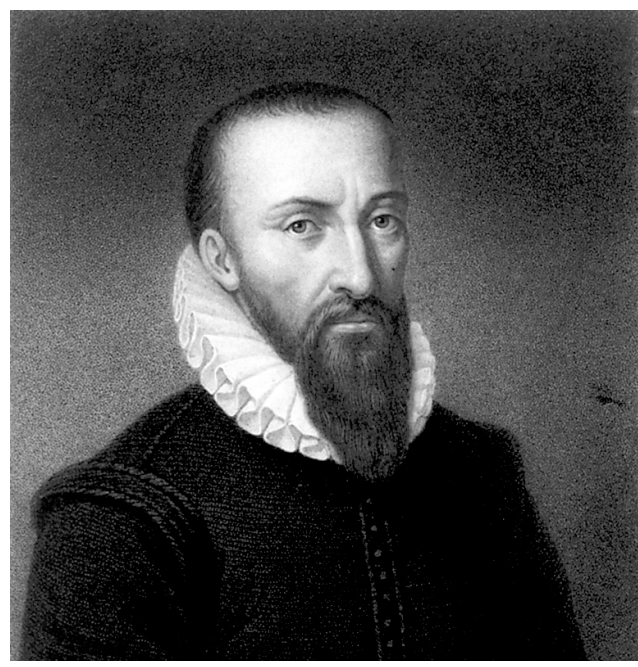

Ambroise Paré (I 5 IO-I590).

\begin{abstract}
A profissão médica no século XVI compreendia três classes: em primeiro lugar situavam-se os médicos, que possuíam maiores conhecimentos teóricos, usavam o latim em seus escritos e consideravam-se a elite da profissão. Vinham a seguir os cirurgiões, que tratavam feridas e traumatismos externos, faziam amputações, praticavam a talha para tratamento da litíase vesical, lancetavam abscessos e usavam o cautério. Por último estavam os cirurgiões-barbeiros, que faziam sangrias, aplicavam sanguessugas e ventosas, barbeavam seus fregueses e, por vezes, concorriam com os cirurgiões abrindo abscessos e fazendo curativos.

Ambroise Paré viveu de I 5 IO a I 590 . Não era médico e iniciou sua carreira como aprendiz de cirurgião-barbeiro na cidade de Laval, no interior da França. Ainda jovem transferiu-se para Paris e, aos dezenove anos, conseguiu o que mais desejava - trabalhar no Hôtel-Dieu, o mais antigo hospital de Paris. Ali praticou durante quatro anos como auxiliar de cirurgia, observando e participando do tratamento de feridos. Demonstrou, desde o início, sua habilidade cirúrgica e interesse em aprender. Capacitou-se de tal maneira na prática da cirurgia
\end{abstract}


que foi indicado como cirurgião militar do exército francês, participando das campanhas da Itália de I 536 a I 545 (Mondor, I947, pp. 68-7I).

Sua primeira grande contribuição à medicina ocorreu quando contava 26 anos e relaciona-se ao tratamento dos feridos por arma de fogo.

Até o século XVI acreditava-se que as feridas produzidas por armas de fogo eram envenenadas. Conforme ensinava Vigo, conceituado cirurgião e traumatologista italiano, as mesmas deviam ser cauterizadas com ferro em brasa ou óleo fervente para combater a ação tóxica da pólvora. O prestígio de Vigo no meio médico europeu pode ser avaliado pelo fato de sua obra Practica in chirurgia, publicada em I 5 I 4, ter alcançado trinta edições. Seus princípios terapêuticos eram considerados a última palavra da ciência e jamais eram contestados (Major, I954, pp. 37I-373).

Uma casualidade concorreu para que Ambroise Paré se insurgisse contra este tipo de tratamento e vamos narrá-la com suas próprias palavras:

No ano do Senhor de 1 536, Francisco, rei de França, mandou um poderoso exército para lá dos Alpes. Eu era, no Exército Real, o cirurgião do Senhor de Montejan, general de infantaria. Os inimigos tinham tomado os desfiladeiros de Suza, o castelo de Villane e todos os demais caminhos, de modo que o exército do rei não era capaz de expulsá-los de suas fortificações senão pela luta. Houve neste embate, de ambos os lados, muitos soldados com ferimentos produzidos pelas armas mais diversas, sobretudo por bala. $\mathrm{Na}$ verdade, não estava muito versado, naquela época, em questões de cirurgia, nem estava acostumado a fazer curativos em ferimentos por arma de fogo. Lera que os ferimentos por arma de fogo estavam envenenados; portanto, para seu tratamento era útil queimá-los ou cauterizá-los com óleo fervente misturado com um pouco de teriaga. Mas ainda que não desse crédito ao remédio, quis, antes de correr o risco, ver se os outros cirurgiões que estavam comigo na tropa usavam qualquer outro curativo para esses ferimentos. Observei e verifiquei que todos usavam o curativo prescrito.

Aconteceu que, certa vez, devido à multidão de feridos, faltou óleo. Então, porque ficassem alguns sem curativo, fui forçado, porque podia parecer que não queria fazer nada e não podia deixá-los sem tratamento, aplicar uma mistura feita de gema de ovos, óleo de rosas e terebentina.

Durante aquela noite não pude dormir porque estava com o espírito conturbado e o curativo da véspera, que eu julgava impróprio, perturbava os meus 
pensamentos e temia que no dia seguinte ia encontrá-los mortos ou a pique de morrer devido ao veneno da ferida que não tratara com óleo fervente. Portanto, acordei cedo e, fora de qualquer expectativa, notei que aqueles tratados sem o óleo estavam descansados, porque livre da violência de dor e suas feridas não estavam inflamadas nem tumefeitas; entretanto, os outros, queimados pelo óleo fervente, estavam febris, atormentados com muitas dores e tumefeitas as partes que cercavam as feridas.

Depois de ter experimentado isto muitas vezes em diversos outros feridos, considerei muito a respeito que nem eu nem ninguém devíamos cauterizar qualquer ferido por arma de fogo (Castiglioni, I947, pp. 559-56I).

Por sugestão de Sylvius, que conhecera no Hôtel-Dieu, Paré divulgou em I 545 o seu método em um livro intitulado La Methode de traicter les playes faictes par hacquebutes et aultres bastons à feu..., o qual foi mal recebido no meio médico por ter sido escrito em francês por um cirurgião-barbeiro ignorante, que não sabia latim. Por ter sido escrito em francês, entretanto, o livro tornou-se acessível e foi traduzido para outras línguas. Em poucos anos o método de Paré foi adotado por outros cirurgiões, não só na França, como na Alemanha e na Itália.

A segunda importante contribuição de Paré no campo da cirurgia diz respeito à hemostasia dos vasos sanguíneos nas amputações de membros. A conduta usada para deter a hemorragia nesses casos consistia na cauterização com ferro incandescente, procedimento que causava enorme dor nos operados e ocasionava lesões de difícil cicatrização. O próprio Paré utilizou-se deste método clássico até I 552 , quando passou a usar pinças e ligar os vasos com fios, tal como se pratica hoje. Para defender-se das críticas contra o novo método, considerado temerário, Paré citava Hipócrates, Galeno, Avicena e outros autores clássicos que, em seus livros, recomendavam ligar as veias em lugar da cauterização com o ferro incandescente (Beliard, I938, p. I89).

Indiferente às críticas dos meios científicos, Paré prosseguiu em seu trabalho, fazendo suas próprias observações, desenvolvendo e aperfeiçoando as técnicas cirúrgicas. Em I 552 Paré tomou parte em outra expedição militar e Henrique II, rei da França, impressionado com sua habilidade cirúrgica, designou-o cirurgião ordinário do rei. Este fato trouxe prestígio 


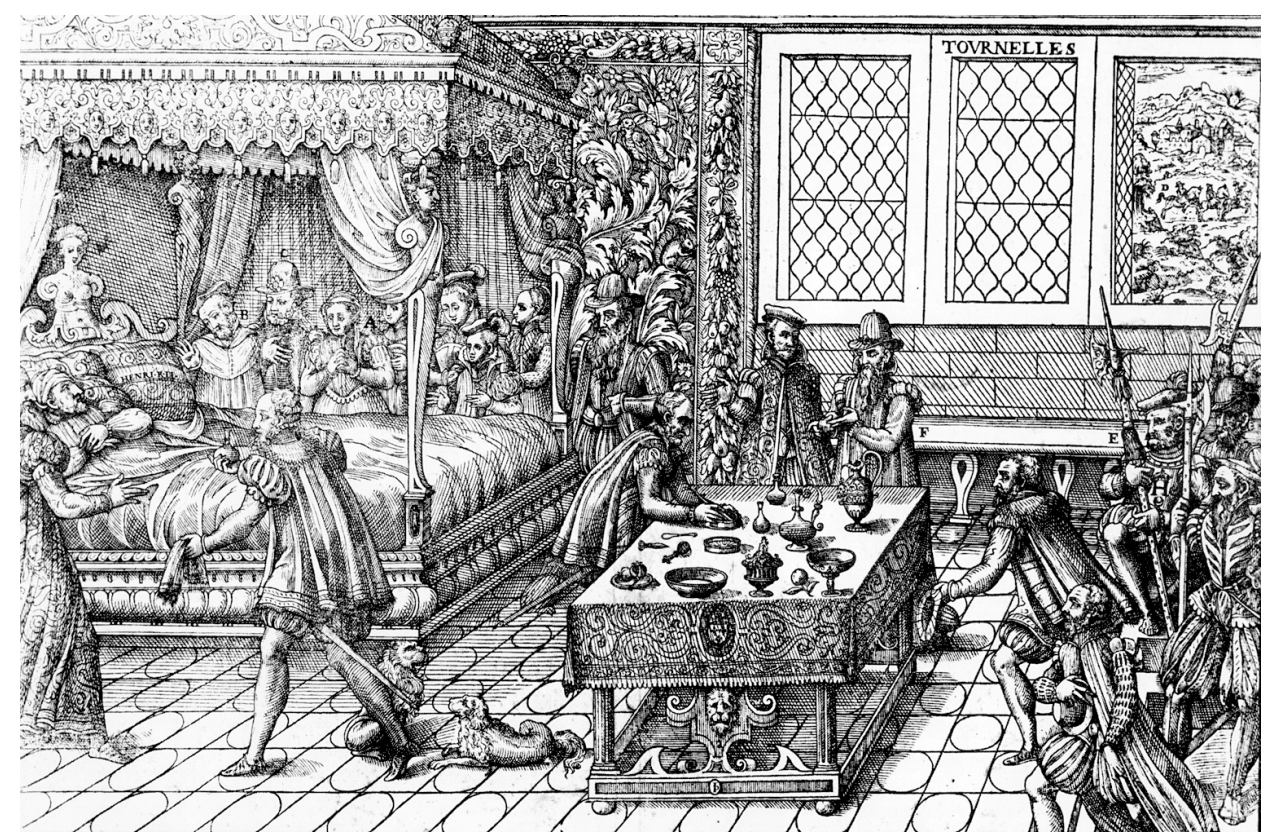

Gravura (c. I560) representa Vesalius e Paré assistindo ao moribundo Henrique II.

a Paré e dois anos depois ele foi admitido na Confraria de São Cosme, que congregava os mais notáveis cirurgiões da França. Foi-lhe concedido o título de mestre em cirurgia, apesar da oposição de alguns membros do colegiado, que não admitiam que alguém que não soubesse latim pudesse pertencer à Confraria.

Henrique II faleceu de um traumatismo craniano, sob os cuidados de Paré e Vesalius. Ocupou o trono Francisco iI, que reinou apenas dezoito meses e foi sucedido por Carlos Ix, que, não somente manteve a posição de Paré, como o promoveu em I 562 à condição de primeiro cirurgião do rei. Paré serviu ainda ao rei Henrique III, sucessor de Carlos IX.

Paré teve uma vida de intensa atividade. Inventou novos instrumentos cirúrgicos, idealizou membros artificiais e o reimplante de dentes, reviveu a versão podálica de Sorano, bem como a operação de lábio leporino e foi o primeiro a perceber que a sífilis era causa de aneurisma da aorta. Apesar de não ser médico publicou um tratado sobre a peste e outras doenças e combateu o uso supersticioso de pó de múmia como medicamento, o que estava em moda na época e chegou a fazer parte do receituário médico. 
Em I 564 publicou Dix livres de la chirurgie e, em I 575, aos 65 anos de idade, reuniu todos os seus trabalhos em 27 volumes sob o título Les oeuvres de M. Ambroise Paré, avec les figures et portraicts tant de l'anatomie que des instruments de chirurgie et de plusieurs monstres (ARA, 200I).

Suas obras continham matéria não relacionada à cirurgia e como Paré não era médico, a faculdade de medicina tentou, sem êxito, impedir a publicação da primeira e da segunda edição. Paré viveu mais quinze anos, durante os quais foram publicadas mais quatro edições de suas obras, e faleceu quando estava preparando a quinta edição, aos oitenta anos de idade. Outras edições se sucederam e Ambroise Paré passou a ser considerado o pai da cirurgia moderna.

Paré, demonstrando humildade e espírito religioso dizia sempre, referindo-se a seus pacientes: "Eu o tratei, Deus o curou".

Paré era tido como huguenote (nome pelo qual eram conhecidos na França os protestantes calvinistas) e escapou de ser morto na noite de São Bartolomeu, a 23 de agosto de I 572, porque o próprio rei Carlos IX, que ordenara a matança, o ocultou no palácio (Major, op. cit., p. I45).

\section{Referências Bibliográficas}

ara - Association Animation Renaissance Amboise. "Ambroise Paré, i 509-i 5 Io", i i

jan. 200I. Disponível em http://www.renaissance-amboise.com/dossier_renaissance/ ses_personnages/Ambroise_Pare/ambroise_pare.php, acesso em 28 ago. 2009.

Beliard, O. "La Renaissance”. In Lavastine, L. Histoire générale de la médecine, vol. 2. Paris, Albin Michel Éditeur, 1938.

Castiglioni, A. História da Medicina, vol. 2. São Paulo, Cia. Editora Nacional, i947. Major, R. H. A History of Medicine. Oxford, Blackwell Scientific Publications, I954. Mondor, H. “Ambroise Paré”. In Dumesnil, R.; Bonnet-Roy. Les medecins celebres. Paris, Ed. Lucien Mazenot, I947. 
